\title{
Kidney Allocation: New Contributions to an Ongoing Challenge
}

\section{Alocação Renal: Novas Contribuições para um Desafio Permanente}

\author{
Nuno MOREIRA FONSECA $\bowtie 1$, Fernando NOLASCO ${ }^{1}$ \\ Acta Med Port 2017 Dec;30(12):833-834 - https://doi.org/10.20344/amp.9947
}

Keywords: Donor Selection; Kidney Transplantation; Portugal; Resource Allocation; Social Justice; Tissue and Organ Procurement Palavras-chave: Alocação de Recursos; Justiça Social; Obtenção de Tecidos e Órgãos; Portugal; Seleção do Dador; Transplante de Rim

Kidney transplantation is the treatment of choice for chronic end-stage renal disease, offering greater survival when compared to dialysis. ${ }^{1}$ The gap between the number of patients and available organs has been steadily increasing. ${ }^{2}$ Currently there is no international consensus on the factors that should be considered in the kidney allocation process. The major debate in the allocation of scarce donor organs centers on the competing ethical values of utility (maximum outcomes) and equity (fairness). ${ }^{3}$ The current Portuguese criteria for allocation include criteria to satisfy both these principles: candidates' waiting time on dialysis and state of hypersensitization for fairness; and maximization of human leukocyte antigen (HLA) compatibility, and age differential between donor and recipient for utility. When this allocation system was introduced, in 2007, one of its main objectives was to mitigate the disadvantage of hypersensitized patients who were subjected to disproportionately longer waiting times. ${ }^{4}$ Ten years later, it is now time to evaluate its outcomes and introduce changes for improvement in light of new clinical data.

Research such as the article "Donor-recipient pair selection in renal transplantation: comparative results from a simulation" ${ }^{5}$ published in this edition of Acta Médica Portuguesa, constitutes an invaluable landmark for future deliberations. This article results from years of investigation led by the authors and has the merit of simulating the application of a new allocation model. ${ }^{3}$ In the authors' proposal organs are distributed among four groups of candidates stratified by time on dialysis and hypersensitization status. Each group is assigned a color: red (clinical urgency), orange (calculated panel reactive antibody (cPRA) $\geq 85 \%$ or dialysis time greater than the $3^{\text {rd }}$ quartile, i.e. dialysis time required until $75 \%$ of the candidates on the waiting list are transplanted), yellow (cPRA $\geq 50 \%$ or with a dialysis time greater than the median of dialysis time required until transplantation), and lastly, green (encompassing the remaining candidates). In this proposal clinical urgency is the top priority. While many allocation systems do not include medical urgency as a criteria, it seems important to recognize that not all patients can afford to wait the same amount of time. ${ }^{3}$

The proposed color priority system improves transparency by rendering allocation more intelligible to patients, and addresses one of the most criticized aspects of current allocation systems: waiting time on dialysis as the primary driver of allocation. ${ }^{6}$ The authors' results suggest that the mere reduction of the scoring currently attributed to dialysis time ( 0.1 points per month) may be insufficient to produce appreciable benefits. Another positive change proposed is the definition of hypersensitization according to calculated panel reactive antibody (PRA) CPRA, instead of PRA by complement-dependent cytotoxicity. The later method unfairly disadvantages hypersensitized candidates, by increasing their waiting time unduly. ${ }^{7}$ Use of cPRA for allocation purposes has already been successfully implemented in other countries. ${ }^{8}$

Having based their simulation on data concerning only HLA genotype distribution of the Portuguese northern population, the authors recognize that it is only possible to estimate the likelihood of obtaining a compatible organ for a specific recipient if national HLA data is available, which is still not the current practice. ${ }^{9}$ In the near future HLA matching is expected to be determined at the epitope level. This will allow identification of more suitably mismatched donors for non-sensitized patients, as well as, acceptable mismatches for sensitized transplant candidates. ${ }^{10}$

Nonetheless, there is a general trend toward a reduction in the influence of HLA mismatch and an increase in the importance of other factors shown to affect the longevity mismatch of organs and recipients. ${ }^{3}$ The new allocation system introduced in the United States (USA) in 2014 allows for a reasonable estimation of recipient's survival and graft longevity, and preferentially allocates kidneys with longer expected duration of function to patients expected to live longer. ${ }^{11}$ In the USA, prediction of graft survival was shown to be significantly improved when considering donor comorbidities (hypertension, diabetes, etc) in addition to age alone. ${ }^{11,12}$ In their simulation the authors

1. Nephrology Department. Centro Hospitalar Lisboa Central. Lisboa. Portugal.

$\square$ Autor correspondente: Nuno Moreira Fonseca. nuno.mf@nyu.edu

Recebido: 15 de novembro de 2017 - Aceite: 06 de dezembro de 2017| Copyright @ Ordem dos Médicos 2017 
propose an old-to-old allocation, similar to that implemented by Eurotransplant, which has presented satisfactory results. ${ }^{13}$

Allocation systems are subject to permanent reform worldwide. Other options currently being discussed include use of hepatitis $C$ virus infected donors, and marginal grafts with a favorable pathology examination..$^{14,15}$ Some countries have also opted to give priority to patients who have previously donated a kidney. ${ }^{16}$ Countries with geographic size similar to Portugal, such as Israel, have opted to allocate organs only at a national level, without any local or regional priority. In allocation systems where this has been implemented, access for disadvantaged patient groups has improved, especially for hypersensitized patients. ${ }^{17}$ However, national shipping of kidneys may create logistical challenges and may increase cold ischemic time, and delayed graft function, as seen in the United States. ${ }^{6,17}$ Other strategies to expand the donor pool have consisted on the use of kidneys retrieved after cardiac death. This that was been legally established in 2013 has yet to achieve its full potential, with only a limited number of transplant centers currently performing it.

\section{REFERENCES}

1. Matas AJ, Smith JM, Skeans MA, Thompson B, Gustafson SK, Stewart DE, et al. OPTN/SRTR 2013 Annual Data Report: Kidney. Am J Transplant. 2015;15:S1-34

2. Sociedade Portuguesa de Nefrologia. Relatório Gabinete de Registo da SPN: Tratamento Substitutivo Renal da Doença Renal Crónica Estádio $\checkmark$ em Portugal. [accessed 2017 Nov 10]. Available from: http://www. bbg01.com/cdn/clientes/spnefro/noticias/130/REGISTO_DRCV2016. pdf.

3. Wu DA, Watson CJ, Bradley JA, Johnson RJ, Forsythe JL, Oniscu GC Global trends and challenges in deceased donor kidney allocation Kidney Int. 2017;91:1287-99.

4. Gonçalves JA, Jorge C, Atalaia A, Matias P, Bruges M, Birne R, et al. New law of renal transplantation in Portugal associated with more acute rejection episodes and higher costs. Transplant Proc. 2012;44:2276-9,

5. Lima BA, Alves $H$. Seleção do par dador-receptor em transplante renal: resultados comparativos de uma simulação. Acta Med Port. 2017:30:854-60.

6. Formica RN Jr. A critical assessment on kidney allocation systems Transplant Rev. 2017;31:61-7.

7. Magriço R, Malheiro J, Tafulo S, Pedroso S, Almeida M, Martins LS, et al. Implications for patients waiting for a kidney transplant of using the calculated panel reactive antibody (cPRA ). Port J Nephrol Hypert. 2016;30:185-93.

8. Valentin MO, Ruiz JC, Vega R, Martin C, Matesanz R, working group PATHI. Implementation of a national priority allocation system for hypersensitized patients in Spain, based on virtual crossmatch: initial results. Transplant Proc. 2016;48:2871-5.

9. Lima BA, Mendes M, Alves H. Hypersensitized candidates to kidney transplantation in Portugal. Port J Nephrol Hypert. 2013;27:77-81.
The implementation of new measures regarding kidney allocation will necessarily affect the current balance between efficiency and fair access. Therefore vigilant monitoring and critical assessment of the outcomes will be necessary from the kidney transplant community as potential consequences could include reduction in transplant rates for specific patient groups. ${ }^{18}$ Despite their inherent limitations, simulations remain the best method to predict future changes.

\section{CONFLICT OF INTERESTS}

Nuno Moreira Fonseca has received funding from Sanofi, Astellas, Menarini (for participation in scientific meetings), AstraZeneca and Bial (participation in continuing medical education activities) and the Fullbright Comission (for postgraduate studies).

Fernando Nolasco has received funding for participation in scientific meetings, consulting, development of research protocols from multiple entities, including the Portuguese Societies of Nephrology and Transplantation, and the pharmaceutical industry (Novartis, Astellas, Roche, Bayer), Diaverum, among others, without a conflict of interest with opinions presented here.

10. Duquesnoy RJ. Are we ready for epitope-based HLA matching in clinical organ transplantation? Transplantation. 2017;101:1755-65.

11. Organ Procurement and Transplantation Network. Concepts fo kidney allocation. [accessed 2017 Nov 10]. Available from: http://optn. transplant.hrsa.gov/.

12. Hernandez RA, Malek SK, Milford EL, Finlayson SR, Tullius SG, et al. The combined risk of donor quality and recipient age: higher quality kidneys may not always improve patient and graft survival." Transplantation. Transplantation. 2014;98:1069-76.

13. Frei U, Noeldeke J, Machold-Fabrizii V, Arbogast $H$, Margreiter R, Fricke L. Prospective age-matching in elderly kidney transplant recipients-a 5-year analysis of the Eurotransplant Senior Program. Am J Transplant. 2008:8:50-7.

14. Fishman JA, Forns X. HCV-positive donor organs in solid organ transplantation. Mind the gap. Am J Transplant. 2017;17:2755-6.

15. Wang CJ, Wetmore JB, Crary GS, Kasiske BL. The donor kidney biopsy and its implications in predicting graft outcomes: a systematic review. Am J Transplant. 2015;15:1903-14

16. Wainright JL, Kucheryavaya AY, Klassen DK, Stewart DE. The impact of the new kidney allocation system on prior living kidney donors' access to deceased donor kidney transplants: an early look. Am J Transplant. 2017:17:1103-11.

17. Stewart DE, Kucheryavaya AY, Klassen DK, Turgeon NA, Formica RN Aeder MI. Changes in deceased donor kidney transplantation one year after KAS implementation. Am J Transplant. 2016;16:1834-47.

18. Wang CJ, Wetmore JB, Israni AK. Old versus new: progress in reaching the goals of the new kidney allocation system. Hum Immunol. 2017;78:9- 